\title{
Faculty Acceptance of the World Wide Web for Student Research
}

\author{
Susan Davis Herring
}

\begin{abstract}
Although undergraduates frequently use the World Wide Web in their class assignments, little research has been done concerning how teaching faculty feel about their students' use of the Web. This study explores faculty attitudes toward the Web as a research tool for their students' research; their use of the Web in classroom instruction; and their policies concerning Web use by students. Results show that although faculty members generally feel positive about the Web as a research tool, they question the accuracy and reliability of Web content and are concerned about their students' ability to evaluate the information found.
\end{abstract}

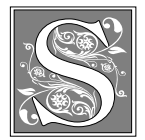

ince its development in 1991, the Web has become a pervasive research source for students on college and university campuses throughout the United States. Increasing computer instruction in elementary and secondary schools and the growing numbers of personal computers in homes have resulted in a high computer literacy rate among students entering college, often higher than that of their instructors, and in a growing familiarity with the use of the Web.

However, despite the Web's popularity and widespread use, and despite the volume of information available, many academic librarians report that students often use the Web inefficiently and appear unaware of its limitations, failing to recognize issues of reliability, validity, or authority. As Cheryl LaGuardia wrote, "users have been set loose (or free, de- pending upon your point of view) across the web, around the world, throughout the online universe, groping for data, grasping at what we may consider information straws." 1

But how do teaching faculty view their students' use of the Web? To work effectively with students engaged in courserelated research, academic librarians need to understand faculty attitudes toward the Web as a research tool. The research described here centers on a survey of fulltime faculty designed to determine faculty attitudes toward their students' use of the Web and toward the acceptability of the Web as a student research tool.

\section{Review of the Literature}

A substantial body of literature already exists on acceptance and use of the Internet and the Web in academia. As pointed out by Susan S. Lazinger, Judit Bar-Ilan, and

Susan Davis Herring is Associate Professor of Bibliography and Engineering Reference Librarian in the M. Louis Salmon Library at the University of Alabama in Huntsville; e-mail: herrings@email.uah.edu. The assistance and suggestions provided by Dr. Marion Paris and Dr. Annabel Stephens were invaluable in the successful completion of this study and are sincerely appreciated. Financial support from the University of Alabama Graduate School and the School of Library and Information Studies is gratefully acknowledged. 
Bluma C. Peritz, this research tends to cluster in three areas: studies of general use patterns; studies of Internet use by librarians and other information professionals; and studies of use by college and university faculty. ${ }^{2}$ However, faculty attitudes toward their students' use of the Internet have yet to be investigated.

Several authors have looked at problems facing faculty and students using the Internet as an educational tool. Bertram C. Bruce and Kevin M. Leander, writing on the use of digital libraries and other information technologies in education, identified major issues in Internet use as perceptions of the value of information, questions concerning authority, and computer anxiety. ${ }^{3}$ Other researchers have focused on questions of the accuracy and reliability of Web sites. Tom Regan noted that poor quality exists even in sites created and maintained by commercial news organizations. ${ }^{4}$ According to Luciano Floridi, the Web may become a powerful source for disinformation (defined as propaganda, incomplete or corrupted information, or censorship) unless some type of quality certification by academic and/ or commercial services is instituted. ${ }^{5}$

A 1999 study by Tschera Harkness Connell and Jennifer E. Tipple tested the accuracy of information on the Web using the AltaVista search engine and a sample of sixty reference questions. The authors found that although 27 percent of the pages provided correct, or mostly correct, answers and only about 9 percent provided wrong answers, 64 percent of the pages provided no answers to the questions at all. ${ }^{6}$ An earlier study by Chuck Koutnik, taking questions from Slavens's Reference Interviews, Questions, and Materials (3rd edition), had a success rate of just under 32 percent. $^{7}$

Kari Boyd McBride and Ruth Dickstein, in a discussion of how students are using the Web, wrote that "what has really changed with the advent of the Web is that students no longer get most of their information for class assignments from reputable print sources in the library." ${ }^{8}$ This echoes Bruce and Leander's concern about "students who imagine that the Internet is the only source worthy of searching" and students who believe "that sources have value by virtue of having an electronic link." ${ }^{\prime 9}$ Ralph Alberico also noted the tendency for students to "accept anything the computer says" and pointed out issues of authority, provenance, intellectual property, and the danger of accepting "factoids," or information taken out of context. ${ }^{10}$

However, several studies have found that students using the Web for research seem satisfied with what they find. Peter Wei He and Trudi E. Jacobson, studying individuals using Internet terminals at the State University of New York at Albany, reported that 97 percent said they found the Internet useful, 45 percent felt they could "find most of the things they need for their research/assignments from the Internet," and 34 percent described the Internet as their most important resource. ${ }^{11}$ A study of students at three southeastern U.S. colleges by Timothy T. Perry, Leslie Anne Perry, and Karen Hosack-Curlin found that more than 40 percent of the students surveyed used the Internet at least once a week on a regular basis, and of these, almost one-half used it to find information. ${ }^{12}$ A survey of students using the Web at Duke University's undergraduate library showed that they frequently use it for academic purposes, are confident about their ability to navigate it, and generally trust its resources. More than 85 percent of the students rated the accuracy of Web resources as moderate to excellent. ${ }^{13}$

Steven R. Knowlton, writing in the New York Times, noted that many educators feel that students do not realize how much of the vast amount of information readily available over the Web is unreliable. ${ }^{14} \mathrm{He}$ quoted one professor who noticed a decline in the quality of his students' papers after they had begun using the Web for research. Also noting the range of quality in Web sites, Bob Duffy and Jennifer Yacovissi wrote: "Does this mean that students will be led astray, fed misinformation by uncredentialed pretenders to expertise? Probably." 15 


\section{Methodology}

The purpose of the current study was to determine faculty attitudes toward their undergraduate students' use of the Web for class-related research. To do this, a survey instrument was designed that included the End-User Computing Satisfaction (EUCS) instrument, some demographic questions, and a series of questions on classroom Web-use policies. Comments were also encouraged.

The EUCS instrument was designed by William J. Doll and Gholamreza Torkzadeh specifically to measure end users' attitudes toward computer programs with which they are familiar. ${ }^{16} \mathrm{Re}-$ spondents indicated how often they would respond positively to a series of questions using a five-point Likert-type scale of "almost never" to "almost always." EUCS scores include factor scores, which focus on the specific factors of content, accuracy, format, ease of use, and timeliness, and an aggregate overall score, which is the sum of the five factor scores.

Over the past ten years, the EUCS instrument has proved to be a valid and reliable method of judging user perceptions of numerous programs designed to deliver textual and numeric information. Although not previously used in research on the Web, it has been used successfully in studies of a variety of management information system applications, including accounts payable, accounts receivable, CAD-CAM, customer service, dispatching, engineering analysis, inventory, personnel, student data, and other management systems; word processing, spreadsheets, database management, electronic mail, payroll, and other administrative programs; digital libraries; and computer simulation. ${ }^{17-20}$

The EUCS instrument used in this study was a modified form of Doll and Torkzadeh's twelve-item EUCS instrument. Four items that had been deleted from the second-stage test instrument were reintegrated into the form because these questions related directly to the Web environment and the issues that surround it. Also, minor changes in the wording of the questions were made to focus the attention of the respondents on the Web.

In addition, a series of six questions designed to determine the Web-use policies that faculty apply to course-related student research was asked. These questions were:

- I tell my students about specific Web sites and require them to use those sites in their assignments.

- I tell my students about specific Web sites and encourage them to use those sites in their assignments.

- I do not tell my students about specific Web sites, but I allow them to use the Web as a resource.

- I allow my students to use Web sites as their only resource for class assignments.

- I allow my students to use Web sites, but only in conjunction with other types of resources (such as print).

- I do not allow my students to use the Web as a resource for class assignments.

\section{Many faculty indicated that they either limit their students' use of the Web, direct students to specific sites, or require students to get permission to use specific sites.}

These six questions were answered on a Likert-type scale of "almost never" to "almost always."

After pilot testing, a packet containing a cover letter, the survey instrument, and a return envelope was mailed to 1,129 fulltime faculty in Alabama institutions of higher education. The sample included faculty from both public and private institutions and from two- and four-year colleges and universities. Approximately two to three weeks after the initial mailing, reminders were sent to those who had not responded. A total of 388 usable forms were returned by the end of the survey period. The returned surveys are proportionally representative of the three different levels of institutions in the state.

Two research questions are considered in this report on the research study:

1. Have faculty accepted the Web as a suitable resource for their undergraduate students' research? 
TABLE 1

Factor and Overall EUCS Scores and $t$-Test Values

\begin{tabular}{lcccccc}
\hline \hline & N & $\begin{array}{c}\text { Expected } \\
\text { Mean }\end{array}$ & $\begin{array}{c}\text { Actual } \\
\text { Mean }\end{array}$ & $\begin{array}{c}\text { Standard } \\
\text { Deviation }\end{array}$ & t value & $\begin{array}{c}\text { Sig. } \\
\text { (2-tailed)* }\end{array}$ \\
\hline Content factor & 358 & 12 & 13.5950 & 2.7533 & 10.961 & .000 \\
Accuracy factor & 355 & 12 & 13.6254 & 2.9368 & 10.428 & .000 \\
Format factor & 363 & 6 & 7.2231 & 1.4014 & 16.629 & .000 \\
Ease-of-use factor & 361 & 9 & 10.7175 & 2.2055 & 14.795 & .000 \\
Timeliness factor & 364 & 6 & 7.3709 & 1.4761 & 17.719 & .000 \\
Overall EUCS score & 340 & 45 & 52.6794 & 8.9307 & 15.855 & .000 \\
& & & & & & \\
$* p<.05$ & & & & & & \\
\hline
\end{tabular}

2. Do faculty encourage their undergraduate students to use the Web as a resource in their course-related research assignments?

Responses to the EUCS form were used to determine faculty satisfaction with the Web as a resource for their students. Responses to the Web-use policy questions were used to determine the level of faculty encouragement of Web use by their students. Overall acceptance of the Web was determined by the combination of the two sets of questions.

\section{Results}

Both the EUCS factor scores and overall scores proved to be significantly higher than the expected means, as shown in table 1 . T-tests against the expected means showed statistically significant differences (alpha $=.05)$ in a positive direction for all factor scores and the overall score.
Responses to the Web-use policy questions also proved to be generally positive, as shown in table 2. Using "sometimes," "often," and "almost always" responses as indicators, results show that more than 77 percent of the faculty respondents encourage their students to use specific Web sites, 50 percent require them to use specific sites, and 73 percent allow them to use the Web without specifying any particular sites. Only 7.1 percent forbid Web use. However, it is interesting to note that more than 83 percent of the faculty require their students to use other resources in conjunction with the Web.

Academic discipline proved to be a significant factor for both EUCS scores and Web-use policy responses. Post hoc analysis showed that faculty in the language and literature disciplines had significantly lower EUCS content and accuracy factor scores and overall EUCS scores

TABLE 2

Web-use Policy Statements: Means and Percentages

\begin{tabular}{|lrrrrrr|} 
Statement & Mean & $\begin{array}{c}\text { Almost } \\
\text { Never }\end{array}$ & Rarely & Sometimes & Often & $\begin{array}{r}\text { Almost } \\
\text { Always }\end{array}$ \\
\hline Require specific sites & 2.4918 & $30.4 \%$ & $19.6 \%$ & $26.6 \%$ & $17.1 \%$ & $6.3 \%$ \\
$\begin{array}{l}\text { Encourage specific sites } \\
\text { Allow use of any sites }\end{array}$ & 3.2316 & $12.8 \%$ & $10.1 \%$ & $33.2 \%$ & $28.9 \%$ & $15.0 \%$ \\
$\begin{array}{l}\text { Allow use of Web as } \\
\text { only source }\end{array}$ & 1.1935 & $14.9 \%$ & $12.2 \%$ & $30.4 \%$ & $23.8 \%$ & $18.8 \%$ \\
$\begin{array}{l}\text { Allow Web use only } \\
\text { in conjunction }\end{array}$ & 3.1069 & $9.2 \%$ & $7.8 \%$ & $21.3 \%$ & $26.7 \%$ & $35.1 \%$ \\
Do not allow Web use & 1.2640 & $86.3 \%$ & $6.5 \%$ & $4.0 \%$ & $.6 \%$ & $2.5 \%$ \\
\hline
\end{tabular}


TABLE 3

Significant Group Differences for Academic Departments

\begin{tabular}{lllrr}
$\begin{array}{l}\text { Dependent } \\
\text { Variable }\end{array}$ & (I) Department & (J) Department & $\begin{array}{c}\text { Mean Diff. Sig.* } \\
\text { (I-J) }\end{array}$ \\
\hline Content & Language \& Literature & Administrative Science & -2.0019 & .012 \\
Accuracy & Science & Social Science & 1.8652 & .018 \\
& & Humanities & 1.8163 & .050 \\
& Language \& Literature & Science & -2.6325 & .000 \\
& & Administrative Science & -1.8400 & .050 \\
& & Education & -2.0839 & .014 \\
& & Health Science & -2.1103 & .018 \\
Format & Science & Social Science & .8799 & .021 \\
Overall EUCS & & & & \\
score & Science & Language \& Literature & 5.7625 & .030 \\
$* p<.05$ & & & & \\
\hline
\end{tabular}

than did faculty in several other disciplines, as shown in table 3. Faculty in the sciences had significantly higher scores for the accuracy and format factors than did faculty from other disciplines.

Considering Web-use policy, faculty in education proved to be most likely to require students to use specific sites, whereas engineering/computer science faculty were least likely to require students to use other sources in conjunction with the Web (see table 4).

Institution type also was a significant factor for satisfaction as measured by the EUCS instrument, with faculty from community/junior colleges showing higher means on both content and accuracy factors than did other faculty, as shown in table 5 .
Neither gender nor age had any significant impact on satisfaction or Web-use policy.

Approximately one-quarter of the survey respondents added comments to the survey. The majority of these comments focused on Web content, accuracy, and reliability, and indicated concern about students' ability to effectively evaluate Web information. A few representative comments are shown here:

- "The biggest challenge for me is to get the students to evaluate the source of the information. Critical thinking skills must be used!"

- "Students tend to accept what they read-on the WWW or in a book-without question. They need to be taught to evaluate a source for accuracy and/or bias."

TABLE 4

Post Hoc Tests of Group Significance for Web-use Policy

\begin{tabular}{|c|c|c|c|c|}
\hline $\begin{array}{l}\text { Dependent } \\
\text { Variable }\end{array}$ & (I) Department & (J) Department & $\begin{array}{c}\text { Mean Diff } \\
\text { (I-J) }\end{array}$ & f. Sig." \\
\hline \multirow[t]{4}{*}{ Require specific sites } & Education & Science & .8360 & .024 \\
\hline & & Social Science & .8360 & .024 \\
\hline & & Humanities & .8440 & .043 \\
\hline & & Language \& Literature & .9954 & .003 \\
\hline \multirow{2}{*}{$\begin{array}{l}\text { Allow Web only } \\
\text { with other sources }\end{array}$} & Language & Engineering/ & & \\
\hline & \& Literature & Computer Science & 1.0742 & .019 \\
\hline
\end{tabular}




\begin{tabular}{|lclcr|}
\hline \multicolumn{5}{c}{ TABLE 5 } \\
& Significant Group Differences for Institution Types & \\
\hline \hline Dependent & (I) Institution & (J) Institution & Mean Diff. & Sig.* \\
Variable & Type & Type & (I-J) & \\
\hline Content & C/J Colleges & Universities & 1.1368 & .014 \\
Accuracy & C/J Colleges & Four-year Colleges & 1.4195 & .035 \\
$* p<.05$ & & Universities & 1.5040 & .002 \\
& & & & \\
\hline
\end{tabular}

- "Many students believe research begins and ends with only what is on WWW, which is most untrue. Many students believe that if information isn't on computer, then it isn't important. Very limited."

- "I am generally pleased with the WWW as $a$ source of useful information; students often treat it as the source of info. However, there is no quality control on WWW info, so it runs the gamut from excellent to useless and outdated."

- "My biggest concern for students is the danger of believing that everything in print on the Web can be trusted as accurate $\mathrm{w} /$ out additional verification."

- "I think it sometimes prevents the students from discovering other ways of gathering info for research, such as community searches and how to use the library intelligently."

Many faculty indicated that they either limit their students' use of the Web, direct students to specific sites, or require students to get permission to use specific sites. Some typical comments included: "I usually select a list of Web sites for student use. That allows me to eliminate sites I find that have less-than-factual information" and "[M]y students have to follow a client and are required to do several teaching projects to the client. Information/handouts/etc. are obtained from the Web-all materials are OK'd by instructor beforehand."

Other issues mentioned by numerous respondents included problems with the organization of Web information, lack of searching skills, and plagiarism.

\section{Analysis and Conclusions}

Three points are clear from the results of this survey. First, the original research questions posed at the beginning of this project can be answered positively. The faculty who participated in this survey have accepted the Web as a suitable resource for their students' class-related research. They encourage students to use it and often give them specific sites to consult.

However, as a second point, most faculty are not satisfied with the Web as a sole source of information for their students to use. This is clearly demonstrated by the fact that the vast majority of faculty require students to use other resources in conjunction with the Web. And finally, they have some serious doubts about the value, accuracy, authority, and reliability of Web-based information and about their students' ability to evaluate this information after they find it.

These points have distinct consequences for academic librarians. Clearly, academic librarians should accept the Web as a legitimate research resource, make it available to library users, and teach those users how to use it efficiently. In addition, because many faculty have doubts about their students' ability to use the Web and the information they find there effectively, this is an appropriate point for the introduction of information literacy training by library faculty, as suggested by many librarians, including Helge Clausen and Lorie Roth..$^{21,22}$

The importance that faculty place on use of other resources in addition to the Web strongly suggests that traditional library resources will continue to be a necessary component of student research. Therefore, libraries must continue to develop their print resources in conjunction 
with providing access to electronic resources, at least for the foreseeable future.

\section{Recommendations}

The conclusions above suggest several recommendations. First, academic library professionals should be proactive in working with teaching faculty to develop course-related training aimed at enabling students to find Web-based information effectively and to evaluate its quality, authority, and credibility. By taking the initiative in this instructional area, academic librarians can offer needed assistance to faculty and also increase their level of professional authority and visibility within the institution. Moreover, librarians should build components on Web search skills and evaluation techniques into library instruction classes, orientation programs, and tours, as well as in one-onone instruction. Special emphasis should be placed on effective search techniques and evaluation skills focusing on quality criteria, such as the authority and credibility of sources and the accuracy, reliability, and validity of content.

Second, librarians should work in conjunction with subject faculty to select appropriate sites for student use. This activity may involve different levels of effort and types of end products, ranging from selection of a few recommended sites for demonstration to specialized site lists, or "webliographies," for class use, to the development of specialized Web pages providing access points or gateways to authoritative Web information.
This type of service can be viewed as an expansion of traditional collection development activities, taking into consideration both the needs of the curriculum and the special difficulties facing students and faculty in determining the value and quality of Web information. Many librarians are already involved in this activity but are not always guided by coordinated efforts with teaching faculty.

Finally, library administrators and collection development specialists should remember that although faculty accept the Web as a suitable tool for their students' research, they do not consider it a sufficient resource in either quantity or quality of research information available. Therefore, libraries must continue to develop traditional print resources along with electronic resources. This point needs to be made clear to budget-minded institutional administrators who may try to cut library materials funds on the basis that the Web is making "all" information available on everyone's desktop "for free."

\section{Future Research}

The research study described here was limited to faculty at institutions of higher education in the state of Alabama and, as such, is intrinsically nongeneralizable. However, the results are significant and can offer important points of consideration for all academic librarians. Expansion of the study beyond the state is planned. If similar results are found for the larger study, the power of the research will be greatly enhanced.

\section{Notes}

1. Cheryl LaGuardia, “Online Links: Users' Needs, Librarians' Roles,” Library Journal (Nov. 15, 1998): S10-S11.

2. Susan S. Lazinger, Judit Bar-Ilan, and Bluma C. Peritz, "Internet Use by Faculty Members in Various Disciplines: A Comparative Case Study," Journal of the American Society for Information Science 48 (June 1997): 508-18.

3. Bertram C. Bruce and Kevin M. Leander, "Searching for Digital Libraries in Education: Why Computers Cannot Tell the Story," Library Trends 45 (spring 1997): 746-70.

4. Tom Regan, "On the Web, Speed Instead of Accuracy," Nieman Reports 52, no. 1 (spring 1998): 81; available online at Expanded Academic Index ASAP, Article A20624184.

5. Luciano Floridi, "Brave.Net.World: The Internet as a Disinformation Superhighway?" Electronic Library 14 (Dec. 1996): 509-14.

6. Tschera Harkness Connell and Jennifer E. Tipple, "Testing the Accuracy of Information on the World Wide Web Using the AltaVista Search Engine," Reference and User Services Quarterly 18 
(summer 1999): 360-67.

7. Chuck Koutnik, "The World Wide Web Is Here: Is the End of Printed Reference Sources Near?" RQ 36 (spring 1997): 422-25.

8. Kari Boyd McBride and Ruth Dickstein, "The Web Demands Critical Reading by Students," Chronicle of Higher Education (Mar. 20, 1998): B6.

9. Bruce and Leander, "Searching for Digital Libraries in Education," 754.

10. Ralph Alberico, "Serving College Students in an Era of Recombinant Information," Wilson Library Bulletin 69, no. 7 (Mar. 1995): 29-32, 119.

11. Peter Wei He and Trudi E. Jacobson, "What Are They Doing with the Internet? A Study of User Information Seeking Behaviors," Internet Reference Services Quarterly 1, no. 1 (1996): 31-51.

12. Timothy T. Perry, Leslie Anne Perry, and Karen Hosack-Curlin, "Internet Use by University Students: An Interdisciplinary Study on Three Campuses," Internet Research: Electronic Networking Applications and Policy 8, no. 2 (1998): 136-41.

13. John Lubans Jr., "How First-year University Students Use and Regard Internet Resources" (Perkins Library, Duke University, 1998); available online at http:/ /www.lib.duke.edu/lubans/ docs / 1styear/firstyear.html (26 March 1998).

14. Steven R. Knowlton, "How Students Get Lost in Cyberspace," New York Times, 2 Nov. 1997, A18.

15. Bob Duffy and Jennifer Yacovissi, "Seven Self-contradicting Reasons Why the Worldwide Web Is Such a Big Deal," Proceedings of the 17th National Online Meeting (1996): 81-90.

16. William J. Doll and Gholamreza Torkzadeh, "The Measurement of End-user Computing Satisfaction," MIS Quarterly 12 (June 1988): 259-74.

17. William J. Doll, Weidong Xia, and Gholamreza Torkzadeh, "A Confirmatory Factor Analysis of the End-User Computing Satisfaction Instrument," MIS Quarterly 18 (Dec. 1994): 453-61.

18. Anthony R. Hendrickson, Kristy Glorfeld, and Timothy Paul Cronan, "On the Repeated Test-Retest Reliability of the End-User Computing Satisfaction Instrument: A Comment," Decision Sciences 25 (July / Aug. 1994): 655-65.

19. Jin Taek Jung, "Measuring User Success in the Digital Library Environment" (Ph.D. diss., Drexel University, 1997).

20. Roger McHaney and Timothy Paul Cronan, "Computer Simulation Success: On the EndUser Computing Satisfaction Instrument: A Comment," Decision Sciences 29 (spring 1998): 52536.

21. Helge Clausen, “Internet Information Literacy: Some Basic Considerations," Libri 47 (Apr. 1997): 25-34.

22. Lorie Roth, "Educating the Cut-and-Paste Generation," Library Journal (Nov. 1, 1999): 42 44. 